

\title{
Research Article: Nutrition knowledge on jackfruit- A comparative study among farmers and non-farmers of Thrissur district in Kerala
}

\section{N. Mridula and Baiju Thoppil}

Article Chronicle: Received :

14.08.2019;

Revised :

07.10.2019;

Accepted :

14.10.2019

\section{KEY Words:}

Nutrition knowledge, Jackfruit, Farmers, Non-farmers
Author for correspondence :

\section{N. Mridula}

Central Training Institute (KAU), Mannuthy

(Kerala) India

Email: mridulanarayanan

@gmail.com
SUMMARY : Jackfruit is a super food that is truly organic, nutrition packed and that gives a good yield without substantial input. However, the public has not utilized its possibilities, commercially and nutritively. Resultantly much of this nutrition-packed fruit and its parts are wasted, making jackfruit an underutilized fruit crop. Kerala government declared jackfruit as the state fruit crop in March 2018. In this circumstance, the present study was taken upto explore the nutrition knowledge of the farmers and non-farmers regarding jackfruit and its various parts. The study was conducted by randomly selecting 65 farmers and 65 non-farmers from the various Panchayats of Chavakkad, Ollukkara, Puzhakkal and Kodakara blocks of Thrissur district in Kerala state. Assessment of the knowledge score indices showed that significant difference existed between the trained and untrained non-farmers as well as the among trained and untrained farmer populations. Also, it was seen that the females showed higher knowledge score indices among the non-farmers. This study urges the government and the concerned departments to conduct more trainings and awareness campaigns on the nutritional aspects of jackfruit so that it can contribute to local food security, can create additional income to farming families and SHGs through value addition and marketing and enable the agripreneurs to start new enterprises based on it, thus, augmenting the rural economy.

How to cite this article : Mridula, N. and Thoppil, Baiju (2019). Nutrition knowledge on jackfruit- A comparative study among farmers and non-farmers of Thrissur district in Kerala. Agric. Update, 14(4): 288-293; DOI : 10.15740/HAS/AU/14.4/288-293. Copyright@ 2019: Hind Agri-Horticultural Society. 